\title{
15 From Local to Global (and Back): Towards Glocal Ethnographies of Cultural Tourism
}

\author{
Noel B. Salazar
}

\section{The Local-to-global Nexus}

Tourism, the multifaceted global phenomenon of travel for leisure, offers many fascinating research topics across disciplines. Ethnographic research on cultural tourism has come a long way, from ethnographers ignoring tourists during their fieldwork and disregarding the seriousness of tourism research (Lévi-Strauss, 1955) to cultural anthropologists taking active roles in tourism planning and development (Wallace, 2005). Nowadays, tourism is seen as one of the exemplary manifestations of global flows that blur traditional territorial, social and cultural boundaries and create hybrid forms. Perhaps more than any other practice, tourism demonstrates (in the absence of a clearly identifiable hegemonic power) the importance of multiple centres from which people, ideas and capital circulate across the globe and interact dialectically with local circumstances.

Travel destinations worldwide are adapting themselves to rapidly changing global trends and markets while trying to maintain, or even increase, their local distinctiveness. This competitive struggle to obtain a piece of the lucrative tourism pie becomes a question of how 'the local' is (re)presented. On the one hand, global marketing companies and national as well as local authorities play a crucial role in manufacturing and selling destination images and imaginaries. On the other hand, tourism stimulates localization, a dynamic process characterized by the resurgence of competing socio-culturally defined local identities (Cawley et al., 2002). There are many weaknesses associated with stressing local, national, regional or global processes separately. Apart from acknowledging the fact that power relations in tourism operate on different levels, it is necessary to link those levels theoretically and methodologically.

In my own research, I explore the discourse, politics and practices of tour guiding, by way of a multi-sited and multitemporal ethnography of local tour guides in Yogyakarta, Indonesia and Arusha, Tanzania (Salazar, 2005, 2006b, 2007, 2008, 2010). This chapter deals solely with the Asian part of my study. I chose to focus on tour guides because they are key vehicles through which local-to-global flows are articulated. Understanding how and why these cultural mediators create, negotiate and transform the meanings of cultural heritage for tourists and local people reveals new insights about how processes of worldwide interdependence and convergence and local differentiation intersect, overlap and conflict. In what follows, I describe a novel ethnographic methodology to capture the intricacies of the 
local-to-global nexus. I discuss how it is distinct from other approaches and why it is particularly useful when researching cultural tourism. I then present the challenges I faced with this methodology during my own research in Yogyakarta. I end with a critical reflection on the use of glocal ethnography in cultural tourism studies.

\section{Glocal Ethnography}

\section{What's in a name?}

The holistic mixed-methods contribution of socio-cultural anthropology to tourism studies is widely acknowledged (Nash, 2000; Palmer, 2001; Smith and Brent, 2001; Graburn, 2002; Wallace, 2005; Leite and Graburn, 2009). The interpretive approach characterizing this discipline is ethnography, a methodology that has been applied successfully to the study of tourism, especially in developing countries (Moon, 1989; Crick, 1994; Van den Berghe, 1994; Picard, 1996; Bras, 2000; Dahles, 2001; Causey, 2003; Ness, 2003; Yamashita, 2003; Bruner, 2005; Adams, 2006; Wynn, 2007; Cole, 2008). In the strict etymological sense of the term, ethnography refers to something that is written about a particular group of people. The basis for this descriptive writing is an extended period of fieldwork, which traditionally involves participant observation but very often includes other methods such as interviews, surveys and questionnaires (Bernard, 2006). More broadly, ethnography is used to describe a kind of research methodology whose characteristics include sharing in the lives of those under study, gaining an emic understanding of things, a holistic approach and the observation of everyday life. Because theory has tended to lag behind mere ethnographic description, academics now stress the need to link fieldwork with theoretical development (Snow et al., 2003).

Twenty years after the so-called 'crisis of representation', much of which was centred on the question of ethnographic authority, ethnography as a research methodology is facing a new challenge: What do detailed studies of the local tell us about the global and globalization, the complex process of growing worldwide interdependence and convergence? Critics have pointed out that much ethnographic writing invokes notions of the global or globalization, rather than empirically analysing them. The result is ethnography situated within an imagined, if not imaginary, global context or studies of globalized processes that lack ethnographic detail. Underpinning such criticisms is a perfectly understandable intellectual tension. On the one hand, there is the persistent question as to whether ethnographic research of the global is possible. On the other hand, there is a clear recognition that this question does not make much sense since it is not feasible to fully separate the local from the global (Marcus, 1998). Scholars still have a long way to go in understanding exactly how local-to-global scales are connected, disconnected and reconnected. The fact that such linkages exist is indisputable; the major problem is how to operationalize them so that they can be studied and analysed.

Contemporary anthropological theorizing acknowledges that 'the local' refers not solely to a spatially limited locality (Gupta and Ferguson, 1997); above all, it is a sociocultural metaphor for a collectively imagined space inhabited by people who have a particular sense of place, a specific shared way of life and a certain ethos and worldview. It is the site where supralocal processes and flows fragment and are localized, transformed into something place-bound and peculiar. The local is constructed in contradictory ways and has always been, at least in part, the product of outside influences (Appadurai, 1996: 178-199). The global and the local should certainly not be treated as binary oppositions. The localglobal dichotomy is artificial; it arose as a heuristic necessity to meet the shortcomings of a model that tied group and sociocultural characteristics to territory and simply saw the global as a metaphor for all that the model cannot account for. Globalization theories too easily encourage the equation of an abstract global with capital and change versus a concrete local for national) with labour and tradition. In 
reality, processes of globalization and localization assume numerous forms connected by highly unequal power relations. It is therefore more accurate to employ a relational understanding to globalization than a territorial one. Globalization always takes place in some locality, while the local is (re)produced in the global circulation of products, discourses and imaginaries. In other words, the local does not oppose but constitutes the global, and vice versa (Tsing, 2005). Tourism nicely illustrates how the processes of all place making and force making are both local and global, i.e. both socially and culturally particular and productive of widely circulating interactions.

\section{The conundrum of scale}

Because globalizing processes operate across time and space, traditional ethnographic methods, which tend to be placebound, must be supplemented with information linking the particular research moment to the broader context, and the research site(s) to the broader translocal forces, connections and imaginations that constitute the global (Robbins and Bamford, 1997). The fundamental methodological challenge that the condition of localities in current interconnected conditions poses is one of scale. How well can we encompass increasingly wider and complex contexts of analysis? Scale is not the same as size; it has to do with the presence or absence, and relative efficacy, of overarching institutions, not geographic or demographic extent.

Robertson (1995) develops the notion glocalization to better grasp the many interconnections of the local-global nexus. He argues against the tendency to perceive globalization as involving only large-scale macro-sociological processes, neglecting the way in which globalization is always localized. In other words, the local contains much that is global, while the global is increasingly penetrated and reshaped by many locals. The term glocalization captures the dynamic, contingent and two-way dialectic between the two realms. Glocalization invites us to rethink ethnography's conventional scale, treating the local as a space contained or encompassed by larger spaces. The main ethnographic advantage of rethinking the local is the possibility of reclaiming some of the questions that the conventions of scale ordinarily preclude.

There are two major ways to address the conundrum of scale. First, one can scale vertically ('scale up'), by providing closegrained analyses of how a single site is connected locally, nationally, regionally and globally. Traditional fieldwork, however, may be just the beginning if the goal is deep understanding. Instead of cherishing a fetishistic obsession with participant observation, therefore, we need to reinforce this traditional technique with other methods. Gupta and Ferguson (1997: 38), for instance, call for bringing in a multitude of other forms of representation besides fieldwork: archival research, the analysis of public discourse, interviewing, journalism, fiction or statistical representations of collectivities. Using the extended case study method, Burawoy (2000) describes a set of strategies for combining abstract, theoretical insights about globalization with concrete, historically contextualized, geographically situated practices, an approach he and his team of researchers term 'global ethnography'. Vertical scaling can also include a multitemporal (longitudinal or historical) dimension. The presence of these new types of material may require, and also provide openings for, new skills of composition and synthesis (Hannerz, 2003: 35).

The second strategy is to scale horizontally ('scale out'), by including more than one site in the analysis. For many ethnographers, the global is an emergent dimension for exploring the connections among sites. This latitudinal approach is better known in anthropology as 'multi-sited ethnography' (Marcus, 1998). Such a research strategy maintains the local focus of ethnography while at the same time it complicates the definition and construction of the larger system. Multi-local or multi-sited research might actually not be an adequate description, as many places are somehow linked or networked to each other - what Hannerz (2003: 21) calls a 'network of localities' or 
'several fields in one'. A single site within a complex society may be conceptualized as a multiple site, whereas multiple localities can be seen as 'a single geographically discontinuous site' (Hage, 2005). Hannerz (2003: 21) therefore advocates 'translocal' research, clarifying the nature of relations between localities. While the analytical entity is translocal or glocal, the fieldwork is multi-local, because the ethnographer is always somewhere. Merry (2000: 130), on the other hand, proposes a 'deterritorialized ethnography', not restricted to predefined sites but following patterns of circulation.

Building on Robertson's (1995) conceptual framework, I propose the neologism glocal ethnography to describe my own research in Yogyakarta, Indonesia (see Table 15.1). I define glocal ethnography as a fieldwork methodology to describe and interpret the complex connections, disconnections and reconnections between local-to-global phenomena and processes. This is achieved by firmly embedding and historically situating the in-depth study of a particular sociocultural group, organization or setting within a larger (and ultimately global) context. This happens figuratively by putting the $\mathrm{G}$ of global in front of the concept local: g-local. This implies that the focus is still on the local but that local is now embedded in a larger context. Contrary to Burawoy's (2000) global ethnography approach, the stress is not on the global but on the intricate ways the local is linked to national, regional and global scales (scaling up). Glocal ethnography enriches Marcus's (1998) multi-sited ethnography approach by combining his method of scaling out with methods of scaling up.

Table 15.1. General characteristics of glocal ethnography.

Aim

Research questions

Data gathering

Data analysis

End product

Knowledge claim
Describe and interpret the characteristics, structures and interactions of a particular socio-cultural group or organization in a naturally occurring setting, with all its diversity and multiplicity of voices and situated within a larger (and ultimately global) framework. Find the local in the global and vice versa, by revealing local-to-global meaning and thus glocal complexity

Why do people think and act the way they do and how are these thoughts and behaviours shaped by local-to-global influences? How are people positioned in glocal settings and networks, and how do they interact with each other, especially with significant others? What are the power relationships within and between those various settings and what kind of agency do people have to bring about change on different levels?

Extensive fieldwork, characterized by observation (direct or participant) and various types of interviews with key informants and other significant actors. Sustained presence in the research site(s), combined with an intensive engagement with the everyday life of the people that form the focus of the study. Ancillary data include secondary sources, audio-visual data, news media, documents, archives, the Internet, etc. Given the in-depth approach, one study is usually limited to investigating a small number of cases. Use of exhaustive notes and personal diary entries to record the findings Working initially with unstructured data rather than a closed set of externally imposed analytic categories. Systematic coding and building patterns demand certain procedures, but the choice and development of theoretical frameworks depend on the individual researcher, who adds an etic (outsider) view to the emic (insider) perspectives of the participants. Interpretation of data is usually in the form of elaborate verbal descriptions rather than statistical analysis (but quantification is not excluded)

The primary result takes the form of a coherent descriptive narrative, representing the multiplicity of voices and perceptions of the participants as well as the researcher's own views and interpretations. The final product is a detailed ethnographic account in words, spoken or written, a lecture, article or monograph. Conveying the sense of 'being there', producing unexpected details and conclusions, reflecting the multiple modes of ordering and offering explanations wrapped in 'thick descriptions'

Knowledge and understanding about the complex connections, disconnections and reconnections between glocal phenomena and processes 


\section{A Glocal Study of Tourism}

Cultural tourism offers many possibilities for glocal ethnography, especially where international tourists meet local manufacturers, retailers and service providers in the production, representation and consumption of glocalized tourism goods and services (Yamashita, 2003). As Bruner (2005: 17) elucidates, the 'touristic borderzone' is about the local, but what is performed there takes account of global cross-currents. Most of the local-to-global connections in tourism are marked by inequalities and power struggles (Alneng, 2002). Without using the conceptual framework of glocalization, geographers studying tourism have repeatedly stressed the importance of the globallocal nexus. Chang et al. (1996: 285), for instance, argue that 'the global and the local should be enmeshed in any future theoretical frameworks that are developed to help understand the processes and outcomes of ... tourism'. Similarly, Teo and Li (2003: 302 ) state that 'for tourism, the global and the local form a dyad acting as a dialectical process'. In what follows, I briefly sketch how I have used glocal ethnography to study tourism-related processes in Yogyakarta, Indonesia.

Yogyakarta is the name of one of Indonesia's 33 provinces and its capital city, situated on the island of Java. The region has been participating in international tourism for over 30 years. Since the early stages, it has been promoted by the Indonesian government as 'the cultural heart of Java' (or even Indonesia) and an ideal cultural tourism destination for both domestic and international markets. The most important attractions include the 8th-century Buddhist monument of Borobudur and the 9th-century Hindu temple complex of Prambanan (both recognized in 1991 as UNESCO world heritage sites). The city, with its Kraton, the 18th-century walled palace where the Sultan resides, cherishes its Javanese roots, attracting a large number of painters, dancers and writers. Jogja, as the city is affectionately called by Indonesians, is famous for traditional crafts such as batik (intricate waxresist dyed textiles), silverware, pottery, clothing, woodcarving and wayang kulit (shadow puppets). Although Jogja is a small provincial capital, its population reaching half a million, the city's vibrant communities of artists and students ensure that it is well connected nationally as well as internationally. Interestingly, the current tourism discourses about Jogja, as uttered by the government, by travel agencies, tour operators, marketers and by tour guides, only focus on the renowned heritage sites mentioned above and on the traditional arts and crafts performed or produced in the city itself or in its vicinity (Salazar, 2005).

The core of my research centred on analysing the discourses and practices of local tour guides. More particularly, I wanted to understand how guides in Jogja rely on supralocal networks and resources to better glocalize their tour commentaries about local culture for a varied international audience of tourists. I started my year of fieldwork in December 2005. The fact that I had been in Jogja before on two different occasions seriously reduced the expected cultural shock. Proficiency in Indonesian and other languages proved to be of great value when observing the interactions between tourists and guides and when interviewing people. As is usual for ethnographic fieldwork, I spent considerable time interviewing guides (using various interview formats) and directly observing them while guiding. However, in order to capture how the guides are influenced by global crosscurrents of information and imaginaries promoted by tourism, my research had to include many other facets as well.

\section{Collecting data}

Because tour guides are often the only local people with whom tourists interact for a considerable amount of time, it is in the interest of the authorities to streamline their narratives and practices. In the case of Jogja, guiding is controlled by guidelines and regulations imposed by organizations and institutions at various levels: local (Yogyakarta City Department of Tourism, Arts, and 
Culture), provincial (Yogyakarta Provincial Tourism Office), national (Ministry of Culture and Tourism, Indonesian Guide Association), regional (ASEAN Common Competency Standards for Tourism Professionals Framework, APEC Tourism Occupational Skill Standards) and global (UNWTO, UNESCO, World Federation of Tourist Guide Associations). One of my first fieldwork tasks consisted of contacting these regulatory bodies, interviewing some of their key personnel and obtaining copies of the various laws, directives and guidelines. This is a good example of scaling up.

In addition, I interviewed local tour operators who employ guides (most of whom work on a freelance basis). Although it is Indonesia's second most important destination, Jogja's tourism growth is highly dependent on the development of tourism on the neighbouring island of Bali. This power hierarchy translates on many levels. At the time of my research, for example, the Minister of Culture and Tourism was Balinese. A considerable number of Jogja's tour operators are branch offices from Balinese travel agencies. In other words, it is in Bali that tour packages for Jogja are constructed and sold. Obviously, these larger structural characteristics of tourism are beyond the control of local guides in Jogja.

One way the narratives and practices of guides can be shaped and controlled is through education and licensing. The second step in my research therefore involved investigating how guides are professionally schooled and informally trained. I collected information from tourism academies providing guiding courses, and since many guides in Jogja are autodidacts who did not receive much formal training, I also sent a questionnaire to guides to collect basic demographic information and data on education, guiding, tour preparation and information resources, travel, hobbies and the use of new information and communication technologies. The addresses were provided by the Yogyakarta chapter of the Indonesian Guide Association. Based on the usefulness of the information returned, I contacted 25 respondents to conduct in-depth interviews on the same theme. The licensing of tour guides is in the hands of the Institution of Certification for Tourism Professions, currently outsourced by the local authorities to the semi-private Jogja Tourism Training Centre. The licensing process is controlled by the Yogyakarta City Department of Tourism, Arts, and Culture as well as the Indonesian Guide Association and the Association of Indonesian Tour and Travel Agencies. Untangling this web of interrelated organizations involved interviewing officials working for each one of them.

A major part of the actual fieldwork consisted of extensive observation. As a participant, I joined tourists on 28 tours through central Java. As an observer, I spent countless hours socializing with local tour guides and informally interviewing them. These different types of observation led to hundreds of pages of field notes. The secondmost important source of data was interviews. I conducted and recorded in-depth interviews with 25 guides and semi-structured interviews with six people involved in guide training, five local tour operators and 11 tourism officials at local, national and regional levels. Because I also wanted to find out what local people think about tour guiding, I decided to train my two local research assistants to conduct short, semi-structured interviews and sent them out to converse with people in the respective cities and the surrounding villages. They conducted 35 additional short, structured street interviews. My assistants and I transcribed most interviews shortly after conducting them.

In order to grasp the complexity of tour guiding in Jogja, it is necessary to place the contemporary local tourism scene in a wider historical, politico-economic and socio-cultural context (again, an example of scaling up). During my fieldwork, I undertook background literature research in academic libraries. I frequently consulted secondary media sources such as Indonesian newspapers (Kedaulatan Rakyat, Kompas and The Jakarta Post), magazines (Tempo, Kabare and Inside Indonesia) and websites. Regular discussions with Indonesian anthropologists, tourism scholars and students in Jogja were useful to test some of my preliminary hypotheses and explanations. 
I started collecting data long before I embarked on my fieldwork. I systematically kept track of information appearing on the World Wide Web concerning tourism in Jogja. My research assistants and some local contacts kept me informed about what was happening in Jogja through e-mail and short text messages (SMS).

\section{Flexible fieldwork}

I had planned to spend most time during the high season observing guide-guest interactions and talking to both parties before and after the tours. However, a series of natural disasters - repeated volcanic eruptions, a major earthquake and a minor tsunami seriously altered the course of my research. Many of the guides I was working with lost not only their houses or relatives but their income too, since many tourists cancelled their trip to Jogja. One of the advantages of glocal ethnography is its flexibility to adapt research agendas to such rapidly changing field conditions. Ironically, the calamities provided me with extra data on how closely local-to-global scales are interconnected. I was invited to help as a volunteer with Java Tourism Care, an initiative of a variety of local tourism stakeholders aimed at assisting in the relief, rehabilitation and recovery of the province's tourism sector. I systematically gathered national as well as international news media reports about the disasters in order to compare these with the actual situation on the ground. Because there were so many disparities, I felt the need to start my own anthropological blog (Salazar, 2006a). This offered me an extra opportunity to reflect on the current situation and receive feedback from readers. In addition, I collected the travel warnings issued by the governments of Jogja's largest inbound Western markets (France, the Netherlands and Germany). These could be considered examples of scaling out, because $I$ was researching how other sites were relating to what was happening in Jogja. Finally, I was asked to be a consultant for the Jogja Tourism Information Centre, recently founded by the
Yogyakarta Public Relations Association in collaboration with the Yogyakarta Provincial Tourism Office. While helping the local tourism sector, these new involvements gave me easier access to some of its key players.

The severe 27 May 2006 earthquake revealed many hitherto hidden facets of local tour guiding in Jogja. It stressed how for most people guiding is only a temporary job. After the golden years of tourism (1980s to mid1990s), few people on Java are able to make a living from guiding alone. Most freelance guides now have second jobs as teachers or owners of small businesses (often tourismrelated). In the aftermath of the quake, many of them earned extra income by working as translators and scouts for international NGOs, medical teams and government delegations. The never-ending sequence of catastrophes also disclosed the politics and poetics of the local tourism industry. The local-to-global nexus and the low position guides occupy in the hierarchy of tourism became particularly relevant in the case of the Prambanan temple complex. It took almost a month before international experts from UNESCO came to measure the damage to the world heritage site. During all that time, the monument was closed to visitors. After the assessment, a newly built viewing platform (very similar to the ones erected after 9/11 around Ground Zero, New York) allowed tourists to see the temples from a safe distance, without being allowed to enter them. However, PT Taman Wisata, the Indonesian government enterprise managing the park, decided not to lower the entrance fees (US $\$ 10$ for foreigners). Anticipating tourist complaints, many local travel agencies decided to suspend tours to Prambanan. The few tourists who still visited the temple complex did not want the service of a local guide (approximately US\$5) because they knew that they could not get near the temples anyway. This left the Prambanan guides in a very precarious situation.

This volatile state of affairs shifted my original research design in the direction of an exploration of the extremely fragile position of guides within a glocal tourism context. Although most of them are well networked, they do not seem to be able to capitalize on their translocal connectedness, at least not 
for their work as guides. Furthermore, the local chapter of the Indonesian Guide Association is not in a bargaining position to give its members more job security. I ended my period of fieldwork with a long series of indepth interviews with guides about their work, the current situation, tourism in general, tourists and globalization. These meetings gave me an excellent opportunity to test my interpretations of the preliminary findings. I also talked to tour operators, trying to find out how they value the service of local guides.

\section{Bringing it all together}

My fieldwork revealed the Janus-faced role and liminal positionality of local guides, On the one hand, they act as 'mechanics of glocalization', performing partially as actors of hegemonic forces well beyond their reach. They are part of an expansive but loosely structured global tourism system that represents peoples and places in predefined and scripted ways. Guides are instrumental in tourism because they give the system not only a 'local' but also a human face, giving them an advantage over technological competitors like virtual or mobile tour guides. I call them mechanics because they are usually well skilled and have to labour hard to mirror globally fashionable tourism imaginaries, while selling and telling a message that is clearly not their own and performing under conditions they cannot completely determine. Their project is one of glocalization rather than globalization, because localizing the global and globalizing the local is what international tourism is all about. Local guides are not primary producers of cultural tourism discourse, but in the service encounter with tourists they maintain the tourism system of provisioning as it is, by assuring the continuity and perpetuation of the global chain of imaginaries and giving it a 'local' flavour. This role can be machinelike because at times it appears automatic or even involuntary.

Yet, guiding involves more than simply rehashing memorized screenplays, learned formally or informally. The interactive nature of the enacted guide-guest encounter can lead to results unanticipated by those crafting tourism (marketers, governments, etc.). Various meanings are communicated and negotiated, and personal responses, commitments and rules have to be accepted. On tour, guides are mediating not only cultural differences but also the interests and imaginations of various stakeholders. Guiding, like ethnographic fieldwork, is always, to some extent, improvised, creative and spontaneous, defying complete standardization. While guides perform scripted roles, having various dalang (puppeteers) manipulating their moves (e.g. tour operators, authorities at various levels, law enforcement), they are not like wayang kulit (shadow puppets) with little or no control over their own performances. A glocal ethnographic analysis of guiding practices shows how the content (tourism fantasies) can become detached from the container (the guide). This is most evident in the small talk that takes place in between stretches of guiding narrative and in the metadiscursive comments that guides transmit while guiding.

My findings also illustrated the importance of studying the scales in between the local and the global. The national is certainly not disappearing in the context of cultural tourism. In the international tourism market, dream destinations are still sold as countries: 'Amazing Thailand, dreams for all seasons', 'Croatia, the Mediterranean as it once was', 'Ireland, the island of memories', 'Colombia, the only risk is wanting to stay', 'The hidden charm: Vietnam', 'Live your myths in Greece', etc. Local guides are expected to play the role of unofficial ambassadors of national ideologies, even if countries like Indonesia have little means to enforce and control this. Something tourism scholars should pay increasing attention to is the growing power of regional blocs and associations over national as well as global processes. The increasingly important role of the Association of Southeast Asian Nations (ASEAN) and the Asia-Pacific Economic Cooperation (APEC) in shaping Indonesia's tourism is an illustration of this. It remains to be seen whether regionalism 
indicates the erosion of individual states or if it is a way by which nation states may secure their future by pooling sovereignty and resources.

\section{Understanding the Glocal Aspects of Tourism}

Cultural tourism research can, and does, cover the gamut from global standards of hospitality to dyadic host-guest interactions. For those scholars wanting to conduct in-depth studies, glocal ethnography offers a valuable methodology. Glocal ethnographies draw attention to the multiplicity, specificity and mobility of the tourism structures, discourses and imaginaries that sustain real communities and ways of life. Inl the context of international tourism, such orientation recommends increased analytical attention to the role of brokers or mediators - guides, interpreters, travel agents, accommodation providers, government at all levels and international agencies - prominent in cultural tourism development.

As Yamashita (2003: 148) states, 'what cultural anthropology today should illuminate is the realm which lies between the global and the local'. In a similar vein, Tsing (2005) calls for ethnographies with greater humility, listening skills and attentiveness to local processes, with full analytical scrutiny of every complexity and connection. The potential of this methodology lies not in a reduction of complexity, not in the construction of models, but in what Geertz (1973) called 'thick description'. Ethnographies of cultural tourism only gain in significance when placed in larger geographic and historic frameworks, in complex macro-processes, since combining understanding at the level of experience with the abstractions of impersonal processes is bound to reveal hitherto invisible processes and contingencies. At the same time, we have to pay attention that ethnographies sensitive to translocal dynamics do not resort to potentially misleading assumptions of ethereal global forces.
Ideally, a holistic approach like the one glocal ethnography proposes takes into account the local-to-global nexus. This attention to various scales - spanning from the local, over the national and the regional, to the global - should not imply a trade-off between depth and time. Unfortunately, structural limitations frequently force ethnographers to work in less than ideal circumstances. There is no methodological reason why only one individual should carry out ethnographic research. Ethnography only gains in depth by being a joint enterprise and allowing multivocality. We live in a complex world and understanding it - let alone trying to change it for the better - is a challenging task. Our research should not be determined by theoretical frameworks and methodologies, but rather creatively tack back and forth between theory and method to find answers to pressing questions. All ethnographies of cultural tourism should be analytically glocal, paying attention to the circulation of people, objects or ideas as well as to the institutional and personal domains that standardize but also glocalize them.

As described above, my own experiments with glocal ethnography were not without challenges. While the methodology I propose might help making case studies of 'the local' more relevant by increasing our understanding of the local-to-global nexus, it is not a magical tool that automatically answers all questions. As with other methodologies, much depends on the personal qualities and qualifications of the ethnographer. Take the ethics of the current study, for instance. It is the responsibility of the researcher to resolve moral dilemmas encountered whilst in the field. The degree to which an ethnographer is accountable towards the people he or she is working with depends largely on the researcher's positionality and the context of the study. Under all circumstances, it is important to remain honest and humble and to ensure that the study does not harm or exploit those among whom the research is done. Ethnographers do not possess the truth; neither do the people under study. Ultimately, the receptiveness for multiple points of view gives 
ethnography a great advantage over other methodologies. Echoing Tsing (2005), I would like to call for cultural tourism ethnographies that are grounded (in the glocal), critical and analytical. Tourism scholars have a great opportunity to take the lead, thereby demystifying the common stereotype that all they are able to do is applied research.

\section{Acknowledgements}

This material is based on work supported by the National Science Foundation under Grant No. BCS-0514129 and additional funding from the School of Arts and Sciences,
University of Pennsylvania (USA). 'The research in Indonesia was conducted under the auspices of the Indonesian Institute of Sciences (LIFI Research Permit No. 8093/ SU/KS/2005) and kindly sponsored by Gadjah Mada University. An earlier version of this chapter was presented at the Asia Research Institute's Fifth Graduate Workshop on 'Questions of Methodology: Researching 'Tourism in Asia', National University of Singapore, 5-6 December 2006. The author is most grateful to his colleagues of the Tourism Studies Centre at Gadjah Mada University in Yogyakarta for their useful comments and support. My greatest debt is to the dozens of Indonesians who welcomed me into their homes and lives.

\section{References}

Adams, K.M. (2006) Art as Politics: Re-crafting Identities, Tourism, and Power in Tana Toraja, Indonesia. University of Hawai'i Press, Honolulu, Hawaii.

Alneng, V. (2002) The modern does not cater for natives: travel ethnography and the conventions of form. Tourist Studies 2, 119-142.

Appadurai, A. (1996) Modernity at Large: Cultural Dimensions of Globalization. University of Minnesota Press, Minneapolis, Minnesota.

Bernard, H.R. (2006) Research Methods in Anthropology: Qualitative and Quantitative Approaches, 4th edn. AltaMira, Lanham, Maryland.

Bras, K. (2000) Image-building and Guiding on Lombok: the Social Construction of a Tourist Destination. ATLAS, Arnhem, the Netherlands.

Bruner, E.M. (2005) Culture on Tour: Ethnographies of Travel. University of Chicago Press, Chicago, Illinois.

Burawoy, M. (ed.) (2000) Global Ethnography: Forces, Connections, and Imaginations in a Postmodern World. University of California Press, Berkeley, California.

Causey, A. (2003) Hard Bargaining in Sumatra: Western Travelers and Toba Bataks in the Marketplace of Souvenirs. University of Hawai'i Press, Honolulu, Hawaii.

Cawley, M., Gaffey, S. and Gillmor, D.A. (2002) Localization and global reach in rural tourism: Irish evidence. Tourist Studies 2, 63-86.

Chang, T.C., Milne, S., Fallon, D. and Pohlmann, C. (1996) Urban heritage tourism: the global-local nexus. Annals of Tourism Research 23, 284-305.

Cole, S. (2008) Tourism, Culture and Development: Hopes, Dreams and Realities in East Indonesia. Channel View Publications, Clevedon, UK.

Crick, M. (1994) Resplendent Sites, Discordant Voices: Sri Lankans and International Tourism. Harwood Academic Publishers, Langhorne, Pennsylvania.

Dahles, H. (2001) Tourism, Heritage and National Culture in lava: Dilemmas of a Local Community. Curzon Press, Richmond, UK.

Geertz, C. (1973) The Interpretation of Cultures: Selected Essays. Basic Books, New York.

Graburn, N.H.H. (2002) The ethnographic tourist. In: Dann, G.M.S. (ed.) The Tourist as a Metaphor of the Social World. CAB International, Wallingford, UK, pp. 19-39.

Gupta, A. and Ferguson, J. (eds) (1997) Anthropological Locations: Boundaries and Grounds of a Field Science. University of California Press, Berkeley, California.

Hage, G. (2005) A not so multi-sited ethnography of a not so imagined community. Anthropological Theory 5 , $463-475$.

Hannerz, U. (2003) Several sites in one. In: Eriksen, T.H. (ed.) Globalisation: Studies in Anthropology. Pluto Press, London, pp. 18-38. 
Leite, N. and Graburn, N.H.H. (2009) Anthropological interventions in tourism studies. In: Jamal, T. and Robinson, M. (eds) The Sage Handbook of Tourism Studies. See, London, pp. 35-64.

Lévi-Strauss, C. (1955) Tristes Tropiques. Plon, Paris.

Marcus, G.E. (1998) Ethnography through Thick and Thin. Princeton University Press, Princeton, Massachusetts.

Merry, S.E. (2000) Crossing boundaries: methodological challenges for ethnography in the twenty-first century. Political and Legal Anthropology Review 23, 127-134.

Moon, O. (1989) From Paddy Field to Ski Slope: the Revitalisation of Tradition in lapanese Village Life. Manchester University Press, Manchester, UK.

Nash, D. (2000) Ethnographic windows on tourism. Tourism Recreation Research 25, 29-35.

Ness, S.A. (2003) Where Asia Smiles: an Ethnography of Philippine Tourism. University of Pennsylvania Press, Philadelphia, Pennsylvania.

Palmer, C. (2001) Ethnography: a research method in practice. International Journal of Tourism Research 3 , $301-312$.

Picard, M. (1996) Bali: Cultural Tourism and Touristic Culture. Archipelago Press, Singapore.

Robbins, J. and Bamford, S. (eds) (1997) Fieldwork revisited: changing contexts of ethnographic practice in the era of globalization. Theme issue, Anthropology and Humanism 22(1).

Robertson, R. (1995) Glocalization: time-space and homogeneity-heterogeneity. In: Featherstone, M., Lash, S. and Robertson, R. (eds) Clobal Modernities. Sage, London, pp. $25-44$.

Salazar, N.B. (2005) Tourism and glocalization: 'local' tour guiding. Annals of Tourism Research 32, 628-646.

Salazar, N.B. (2006a) Earthquake disaster: an anthropologist's report from Yogyakarta, Indonesia. Available at: http://web.archive.org/web/*/http://www.museum.upenn.edu/new/research/blogs/earthquake_blog. shtm! (accessed 1 March 2010).

Salazar, N.B. (2006b) Touristifying Tanzania: global discourse, local guides. Annals of Tourism Research 33 , $833-852$.

Salazar, N.B. (2007) Towards a global culture of heritage interpretation? Evidence from Indonesia and Tanzania. Tourism Recreation Research 32, 23-30.

Salazar, N.B. (2008) "Enough Stories!" Asian tourism redefining the role of Asian tour guidés. Civilisations 57, 207-222.

Smith, V.L. and Brent, M.A. (eds) (2001) Hosts and Guests Revisited: Tourism Issues of the 21st Century. Cognizant Communication Corporation, New York.

Snow, D.A., Morrill, C. and Anderson, L. (2003) Elaborating analytic ethnography: linking fieldwork and theory. Ethnography 4, 181-200.

Teo, P. and Li, L.H. (2003) Global and local interactions in tourism. Annals of Tourism Research 30, $287-306$.

Tsing, A.L. (2005) Friction: an Ethnography of Global Connection. Princeton University Press, Princeton, New Jersey.

Van Den Berghe, P.L. (1994) The Quest for the Other: Ethnic tourism in San Cristóbal, Mexico. University of Washington Press, Seattle, Washington.

Wallace, T. (ed.) (2005) Tourism and applied anthropologists: linking theory and practice. Theme issue, NAPA Bulletin 23.

Wynn, L.L. (2007) Pyramids and Nightclubs: a Travel Ethnography of Arab and Western Imaginations of Egypt. University of Texas Press, Austin, Texas.

Yamashita, S. (2003) Bali and Beyond: Explorations in the Anthropology of Tourism. Berghahn Books, New York. 